\title{
Erratum
}

\section{Emotional responses to music: The need to consider underlying mechanisms}

Patrik N. Juslin

Department of Psychology, Uppsala University, SE-75142 Uppsala, Sweden

patrik.juslin@psyk.uu.se

http://www.psyk.uu.se/hemsidor/musicpsy2/

\section{Daniel Västfjäll}

Department of Psychology, Göteborg University, SE-40530 Göteborg, Sweden daniel.vastfjall@psy.gu.se

http://www.psy.gu.se/Personal/DaneilV.htm

The title of the target article by Patrik N. Juslin and Daniel Västfjäll published in Behavioral and Brain Sciences, Volume 31 Number 5 (October 2008), was incorrectly listed on the cover as "All musical emotions are not created equal: The cost of neglecting underlying mechanisms." We regret the error. 